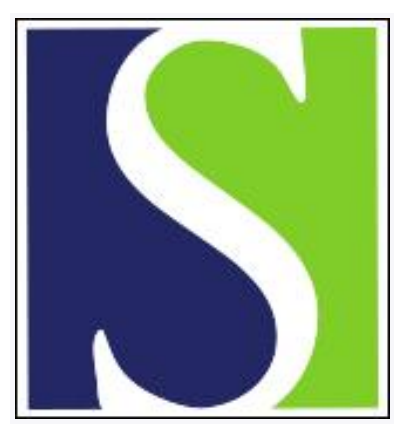

Scand J Work Environ Health 2000;26(1):71-77

https://doi.org/10.5271/sjweh.513

Issue date: Feb 2000

Asbestos-exposed blood monocytes - deoxyribonucleic acid strand lesions in co-cultured bronchial epithelial cells

by Kienast K, Kaes C, Drumm K, Buhl R, Oesch F, Hengstler JG

Key terms: asbestos; blood monocyte; bronchial epithelial cell; deoxyribonucleic acid; deoxyribonucleic acid strand lesion; DNA; epithelial cells; exposure; monocyte; reactive oxygen intermediate

This article in PubMed: www.ncbi.nlm.nih.gov/pubmed/10744181

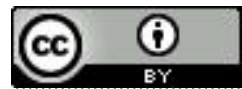




\title{
Asbestos-exposed blood monocytes - deoxyribonucleic acid strand lesions in co-cultured bronchial epithelial cells
}

\author{
by Klaus Kienast, ${ }^{1} \mathrm{C}$ Kaes, ${ }^{1} \mathrm{~K}$ Drumm, ${ }^{1}$ R Buhl, ${ }^{1}$ P Micke, ${ }^{1}$ F Oesch, ${ }^{2}$ JG Hengstler ${ }^{2}$
}

\begin{abstract}
Kienast K, Kaes C, Drumm K, Buhl R, Oesch F, Hengstler JG. Asbestos-exposed blood monocytes - deoxyribonucleic acid strand lesions in co-cultured bronchial epithelial cells. Scand $J$ Work Environ Health 2000;26(1):7177.
\end{abstract}

Objectives In lungs of asbestos-exposed persons alveolar and interstitial macrophages are able to release genotoxic substances such as reactive oxygen intermediates. It is unknown whether reactive oxygen intermediates released by macrophages are able to induce DNA (deoxyribonucleic acid) strand lesions in neighboring bronchial epithelial cells.

Methods A co-culture (transwell) system was established which allows exposure of human blood monocytes cultured on a polycarbonate membrane within a distance of $1 \mathrm{~mm}$ of a monolayer of the bronchial epithelial cell line BEAS-2B.

Results Exposure of blood monocytes to chrysotile B ( $100 \mu \mathrm{g} / 10^{6}$ cells) caused an up to 2.8 -fold increase in DNA strand lesions in co-cultured BEAS-2B cells measured by alkaline elution when compared with the levels of control cells after 1,3,24, and 48 hours. The main DNA damage thus occurred as early as within 1 hour of incubation, corresponding to the time course of the release of reactive oxygen intermediates by blood monocytes determined by chemiluminescence. The maximum release of reactive oxygen intermediates (3.2-fold increase over control values) was measured after 30 minutes of exposure of blood monocytes to chrysotile B. The addition of catalase $(200 \mathrm{U} / \mathrm{ml})$ or desferoxamine $(100 \mu \mathrm{M})$ to the culture medium blocked almost completely the induction of DNA strand lesions in this system (maximum 85\%).

Conclusions Exposure of blood monocytes to chrysotile $B$ results in an increase in the release of reactive oxygen intermediates and induces DNA strand lesions in neighboring bronchial epithelial cells.

Key terms asbestos, deoxyribonucleic acid, epithelial cells, monocytes, reactive oxygen intermediates.

Asbestos is a hydrated magnesium silicate fiber, of which the serpentine, chrysotile $B$, is used for $95 \%$ of industrial purposes $(1,2)$.

Chrysotile $\mathrm{B}$ is deposited in the respiratory tract through impaction, sedimentation, and interception. The physical and chemical properties of the substance make this fiber especially vulnerable to interception at the bifurcations of the bronchioles and alveolar ducts $(3,4)$. No mucociliary transport system exists in this part of the distal respiratory tract ("slow clearance area"). The fibers in this area are known to be taken up by type I alveolar epithelial cells. In addition asbestos fibers have been reported to penetrate into the interstitium after $4-8$ days and have further been observed in capillary endothelial cells and capillary lumina $(5,6)$.
After the incorporation of asbestos fibers the initial lesion is caused by an accumulation of alveolar macrophages in the alveolar ducts and subsequent swelling as a result of a predominance of interstitial macrophages followed by fibroblasts (7). The bronchial and alveolar epithelial cells are injured by mediators released by alveolar macrophages as they attempt to phagocytize free fibers entering the distal respiratory tract. During the phagocytosis of asbestos fibers macrophages release significantly increased amounts of reactive oxygen intermediates (eg, superoxide anion and hydrogen peroxide) (810). The toxicity of oxidant species to bronchial epithelial cells may be a result of the lipid peroxidation of membrane components $(11-16)$. In addition, the release of reactive oxygen intermediates may be responsible for

1 Division of Pneumology, III Department of Medicine, Johannes Gutenberg University, Mainz, Germany.

2 Department of Toxicology, Johannes Gutenberg University, Mainz, Germany.

Reprint requests to: Priv-dozDrmedDiplChem Klaus Kienast, Division of Pneumology, I Department of Internal Medicine, Hospital Erfurt, Nordhaeuser Straße 74, D-99089 Erfurt, Germany. 
mutagenicity $(17-19)$. The generation of reactive oxygen intermediates is able to induce DNA (deoxyribonucleic acid) single-strand breaks. To evaluate whether neighboring epithelial cells are damaged as well, we established a co-culture system in which bronchial epithelial cells are cultured within a distance of 1 millimeter of chrysotile-stimulated human blood monocytes, which are cytologically related to alveolar macrophages. The aim of this study was to investigate whether or not stimulated blood monocytes are able to release mediators which induce DNA single-strand breaks in epithelial cells and whether a potential induction of genotoxic effects can be blocked by antioxidants.

\section{Material and methods}

\section{Isolation of peripheral blood monocytes}

Heparinized venous blood was obtained from 31 healthy, nonsmoking persons [22 men and 9 women, mean age 27 (SD 4) years], none of whom was receiving medication at the time of the investigation. Mononuclear cells were isolated from peripheral blood by Ficoll-density gradient centrifugation (20). The cells were washed 3 times and resuspended in tissue culture medium [macrophage serum free medium (macrophage SFM, Gibco, Karlsruhe, Germany)]. The percentage of the blood monocytes of the total peripheral blood mononuclear cells was determined by Giemsa staining. The mean value for the blood monocytes of the preparations was 34 (SD 9)\%. Pure monocytes were prepared using cell adherence [incubation on the polycarbonate membrane of transwell culture dishes (Costar, Cambridge, USA) in humidified air containing $5 \%$ carbon dioxide at $37^{\circ} \mathrm{C}$ for 45 minutes] and then washed 3 times in culture medium (macrophage SFM, Gibco).

\section{Co-culture}

The BEAS-2B cell line is a SV-40-transformed human bronchial epithelial cell line (obtained from ATCC, \#CRL 9609) (21). BEAS-2B cells were cultured in the

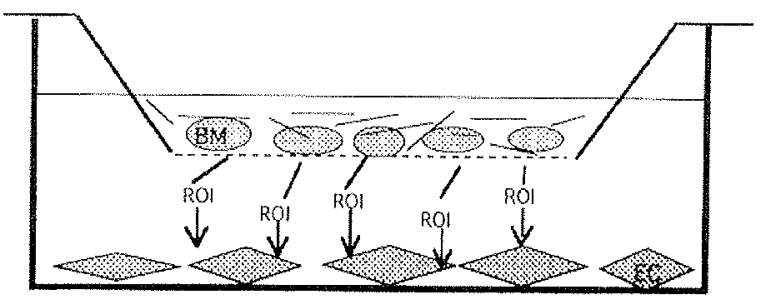

Figure 1. Co-cultured (transwell system) of asbestos-exposed blood monocytes $(\mathrm{BM})$ and bronchial epithelial cells $(\mathrm{EC}) .(\mathrm{ROI}=$ reactive oxygen intermediates) lower compartment of a transwell-plate (Costar) 3 to 4 days prior to the experiments and grown in macrophage serum-free medium at $37^{\circ} \mathrm{C}$ in humidified air containing $5 \%$ carbon dioxide. After the BEAS-2B cells were grown to confluence, freshly isolated blood monocytes were placed onto $3-\mu \mathrm{m}$ pore size polycarbonate membranes (Costar) of the upper compartment of the transwell plate and exposed to fibers (figure 1).

\section{Exposure to particles and treatment with antioxidants}

The asbestos fiber chrysotile B was purchased from the Fraunhofer-Institut (Munich, Germany). The tested fibers ranged in length from 3 to 5 micrometers. Co-cultured blood monocytes were exposed to chrysotile $\mathrm{B}$ at concentrations of 50 and $100 \mu \mathrm{g} / 10^{6}$ cells for $1,3,24$, and 48 hours. The blood monocyte concentration was $10^{6}$ cells $/ \mathrm{ml}$. A chrysotile B concentration of $100 \mu \mathrm{g} / 10^{6}$ cells is therefore equivalent to $100 \mu \mathrm{g} / \mathrm{ml}$. The cells were exposed at $37^{\circ} \mathrm{C}$ in humidified air containing $5 \%$ carbon dioxide.

In the experiments with antioxidants, catalase $(200$ $\mathrm{U} / \mathrm{ml})$, desferoxamine $(100 \mu \mathrm{M})$, or ascorbic acid (100 $\mu \mathrm{M}$ ) (all purchased from Sigma, Deisenhof, Germany) were added to the culture medium of the lower compartment of the transwell system and the co-cultured blood monocytes were simultaneously exposed to chrysotile B at a concentration of $100 \mu \mathrm{g} / 10^{6}$ cells for 3 hours.

\section{Chemiluminescence assay}

The chemiluminescence assay, described by Miles and his co-workers (22), was used for the measurements of reactive oxygen intermediates. Briefly, the reaction mixture, consisting of 100 microliters of freshly prepared luminol (Sigma) solution (a stock solution of $10 \mathrm{mM} \mathrm{lu-}$ minol in dimethyl sulfoxide), was diluted 1:50 in macrophage SFM, 100 microliters of macrophage SFM, and 200 microliters of cell suspension (containing $2 \times 10^{5}$ blood monocytes in macrophage SFM). The cell suspension was pipetted into a prewarmed $\left(37^{\circ} \mathrm{C}\right)$ reaction mixture. The fibers were not removed from the cell suspension after exposure because they did not quench the chemiluminescence signal. The addition of the cells marked the beginning of the reaction period. The measurement time was 15 minutes, during which the peak integral was detected. The data have been presented as peak area counts per 200000 cells/minute.

\section{Standardization of the alkaline elution}

For standardization, BEAS-2B cells were treated with gamma irradiation in a dose range of $0-1000 \mathrm{rad}$, using a cesium irradiation source ( $500 \mathrm{cGy} /$ minute). The cells were stored on ice 15 minutes before, during, and after the irradiation to minimize DNA repair. An almost linear dose-dependent increase in DNA strand lesions was observed (figure 2). 
Determination of deoxyribnucleic acid strand lesions by alkaline elution

Alkaline elution was performed as described elsewhere (23). Briefly, 1 million cells were placed on polycarbonate filters (pore size 2 micrometers, Costar) and lysed at $1.5 \mathrm{ml} /$ hour for 50 minutes (lysing buffer: $2 \mathrm{M}$ sodium chloride, $10 \mathrm{mM}$ ethylenediaminetetraacetic acid, $0.5 \%$ triton $\mathrm{X}-100, \mathrm{pH} 10.0$ ). The elution was performed using an elution buffer ( $5 \mathrm{M}$ sodium chloride, $20 \mathrm{mM}$ ethylenediaminetetraacetic acid, $\mathrm{pH}$ 12.6) at a flow rate of $0.75 \mathrm{ml} /$ hour for 10 hours. An automatic analyzer (San plus System with sampler 1000 and fluorimeter 6300 , Skalar, Breda, The Netherlands) and the DNA-binding fluorescent dye bisbenzimide (Hoechst, Germany) were used for the fluorometric analysis. The relative DNA strand lesion rate $k$ was calculated as $k=-10 \operatorname{lgR}$, where $\mathrm{R}$ is the fraction of DNA remaining on the filter after 10 hours of elution. The elution rates were transformed into $\mathrm{x}$-fold ("relative DNA strand lesion rate") of the control value (=1.0). All of the cell preparations for the measurement of DNA strand lesions by alkaline elution were tested for cell membrane integrity using trypan blue exclusion.

\section{Stastistical analysis}

The data have been presented as the means and standard deviations. The Wilcoxon test for unpaired samples was applied to determine the differences between the treated cells and the controls. P-values of $<0.05$ were considered to be statistically significant.

\section{Results}

Release of reactive oxygen intermediates of chrysotileexposed blood monocytes

Thirty-minute exposure of blood monocytes to chrysotile $B$ at concentrations of 50 and $100 \mu g / 10^{6}$ cells induced a dose-dependent and significant maximum 3.2-fold increase in the release of reactive oxygen intermediates $(\mathrm{P}<0.05$, figure 3$)$. The fiber-induced production of reactive oxygen intermediates in the blood monocytes was inhibited by superoxide dismutase $(100 \mu \mathrm{g} / \mathrm{ml})$. Thirtyminute exposure to chrysotile $\mathrm{B}\left(100 \mu \mathrm{g} / 10^{6}\right.$ cells $)$ resulted in $12.96 \times 10^{5}\left(\mathrm{SD} 4.2 \times 10^{5}\right)$ cells/minute, in comparison with $6.8 \times 10^{5} \pm 2.17 \times 10^{5}$ cells/minute after chrysotile B exposure plus $100 \mu \mathrm{g} / \mathrm{ml}$ superoxide dismutase.

\section{Determination of deoxyribonucleic acid strand lesions in co-cultured BEAS-2B cells after chrysotile $B$ exposure of blood monocytes}

DNA strand lesions were determined in co-cultured BEAS-2B cells after $1,3,24$, and 48 hours of exposure of blood monocytes to chrysotile $B$ at concentrations of 50 and $100 \mu \mathrm{g} / 10^{6}$ cells (figure 4 ). The result was a maximum 1.8-fold increase in DNA strand lesions of co-cultured BEAS-2B cells after a 1-hour exposure period $(\mathrm{P}<0.06)$. Three hours of exposure of blood monocytes to chrysotile B induced a 2.1 -fold $\left(50 \mu \mathrm{g} / 10^{6}\right.$ cells $)$ and 2.2-fold (100 $\mu \mathrm{g} / 10^{6}$ cells) increase in DNA strand lesions of co-cultured BEAS-2B cells $(\mathrm{P}<0.05)$. A 1.9-fold $\left(50 \mu \mathrm{g} / 10^{6}\right.$ cells $)$ and a 2.0 -fold $\left(100 \mu \mathrm{g} / 10^{6}\right.$ cells $)$ increase in DNA strand lesions of co-cultured BEAS-2B were observed after the exposure of blood monocytes to chrysotile $\mathrm{B}$ for 24 hours $(\mathrm{P}<0.1)$. The maximum increase in DNA strand lesions of the co-cultured BEAS-2B was observed after a 48-hour exposure period of blood

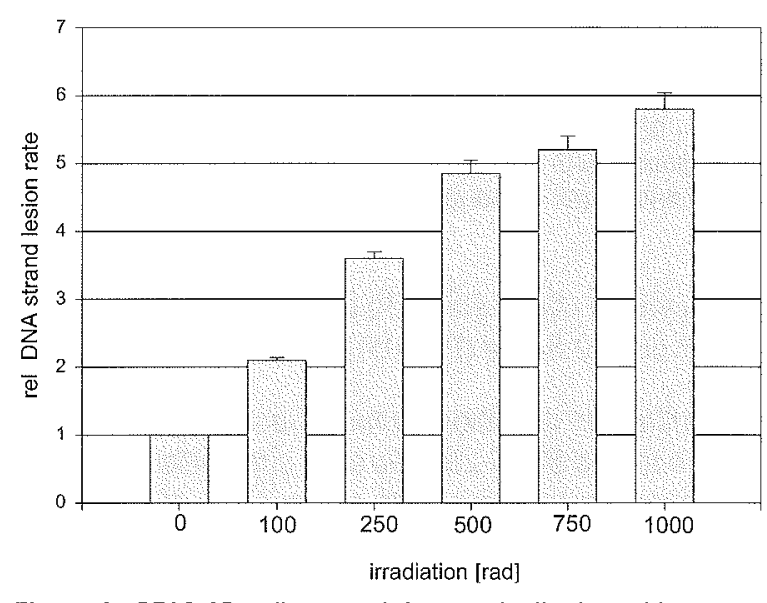

Figure 2. BEAS-2B cells treated for standardization with gamma irradiation at a dose range of $0-1000$ rad, using a cesium irradiation source ( $500 \mathrm{cGy} / \mathrm{minutes})$. Cells were stored on ice 15 minutes before, during, and after the irradiation to minimize DNA repair. (rel = relative)

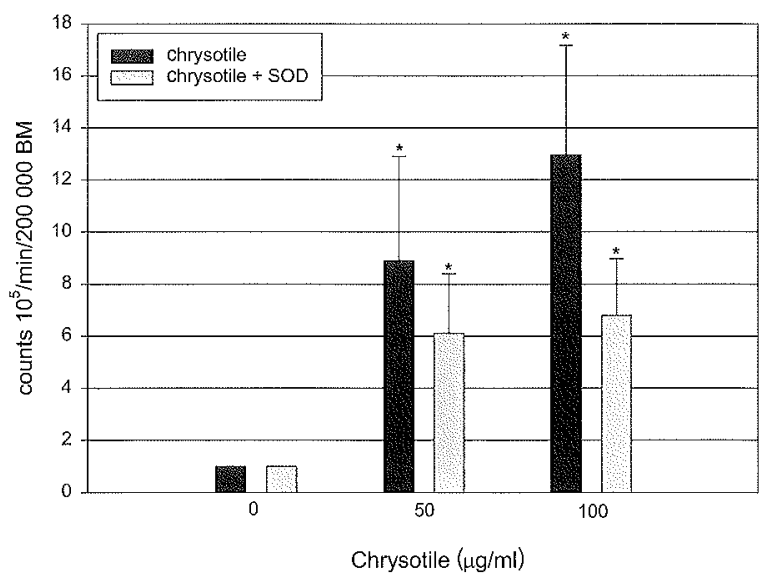

Figure 3. Dose-dependent release of reactive oxygen intermediates of chrysotile-exposed blood monocytes (BM) after 30 minutes of exposure. Fiber concentrations of 50 and $100 \mu \mathrm{g} / 10^{6}$ cells induced a significant maximum 3.2 -fold increase in the release of reactive oxygen intermediates $(P<0.05)$. These findings were verified by the inhibition of the fiber-induced production of reactive oxygen intermediates in blood monocytes after the addition of $100 \mu \mathrm{g} / \mathrm{ml}$ superoxide dismutase (SOD). 


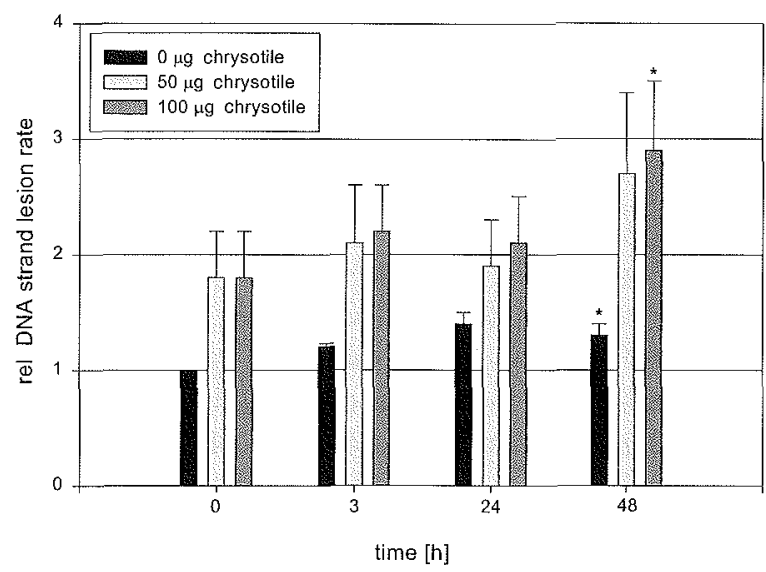

Figure 4. DNA (deoxyribonucleic acid) strand lesions determined in co-cultured BEAS-2B cells after 1, 3, 24, and 48 hours of exposure of blood monocytes to chrysotile $B$ at concentrations of 50 and $100 \mu \mathrm{g} /$ $10^{6} \mathrm{cell}$ s. This exposure pattern resulted in a 1.83 -fold increase in DNA strand lesions of co-cultured BEAS-2B cells after a 1-hour exposure period. The maximum increase in the DNA strand lesions for c0cultured BEAS-2B was observed after a 48-hour exposure period of blood monocytes to chrysotile $B\left(50 \mu \mathrm{g} / 10^{6}\right.$ cells: 2.6 -fold, $100 \mu \mathrm{g} / 10^{\mathrm{b}}$ cells: 2.8 -fold). (rel $=$ relative $)$

monocytes to chrysotile B [50 $\mu \mathrm{g} / 10^{6}$ cells: 2.6 -fold, 100 $\mu \mathrm{g} / 10^{6}$ cells: 2.8 -fold $\left.(\mathrm{P}<0.05)\right]$.

\section{Determination of deoxyribonucleic acid strand lesions in co-cultured BEAS-2B cells after chrysotile $B$ exposure and treatment with antioxidants of blood monocytes}

The antioxidants catalase $(200 \mathrm{U} / \mathrm{ml})$, desferoxamine $(100 \mu \mathrm{M})$, and ascorbic acid $(100 \mu \mathrm{M})$ were added to the respective culture medium and the co-cultured blood monocytes were exposed to chrysotile $B$ at a concentration of $100 \mu \mathrm{g} / 10^{6}$ cells. The DNA strand lesions of cocultured BEAS-2B were determined after a 3-hour exposure period (figure $5 \mathrm{a}$ ) or a 48-hour exposure period (figure $5 b$ ). The induction of DNA strand lesions for cocultured BEAS-2B was almost completely inhibited $(85 \%)$ after the addition of catalase $(\mathrm{P}<0.05)$. Desferoxamine caused an $80 \%$ decrease in the DNA strand lesions of the co-cultured BEAS-2B $(\mathrm{P}<0.01)$. The addition of ascorbic acid induced a $35 \%$ decrease in the DNA strand lesions of the co-cultured BEAS-2B cells $(\mathrm{P}<0.05)$.

The vitality of the co-cultured BEAS-2B cells was assessed using the trypan blue exclusion method after 1 , 3,24 , and 48 hours of exposure of blood monocytes to chrysotile B at concentrations of 50 and $100 \mu \mathrm{g} / 10^{6}$ cells. The maximum decrease in the trypan blue exclusion of co-cultured BEAS-2B cells was recorded after the exposure of blood monocytes to $100 \mu \mathrm{g}$ chrysotile $/ 10^{6}$ cells for an exposure period of 48 hours (17.5\%, figure 6).

\section{Discussion}

The alveolar space and intersitium of the lower respiratory tract is populated with inflammatory cells, which come into close contact with asbestos fibers. Most of these cells are alveolar macrophages, which play an important role in pulmonary defense mechanisms (24). Typical for these cells are inducible reactive oxygen intermediates, which serve as a parameter of cell activity. The release of reactive oxygen intermediates is associated with a "respiratory burst", mediated by the reduced
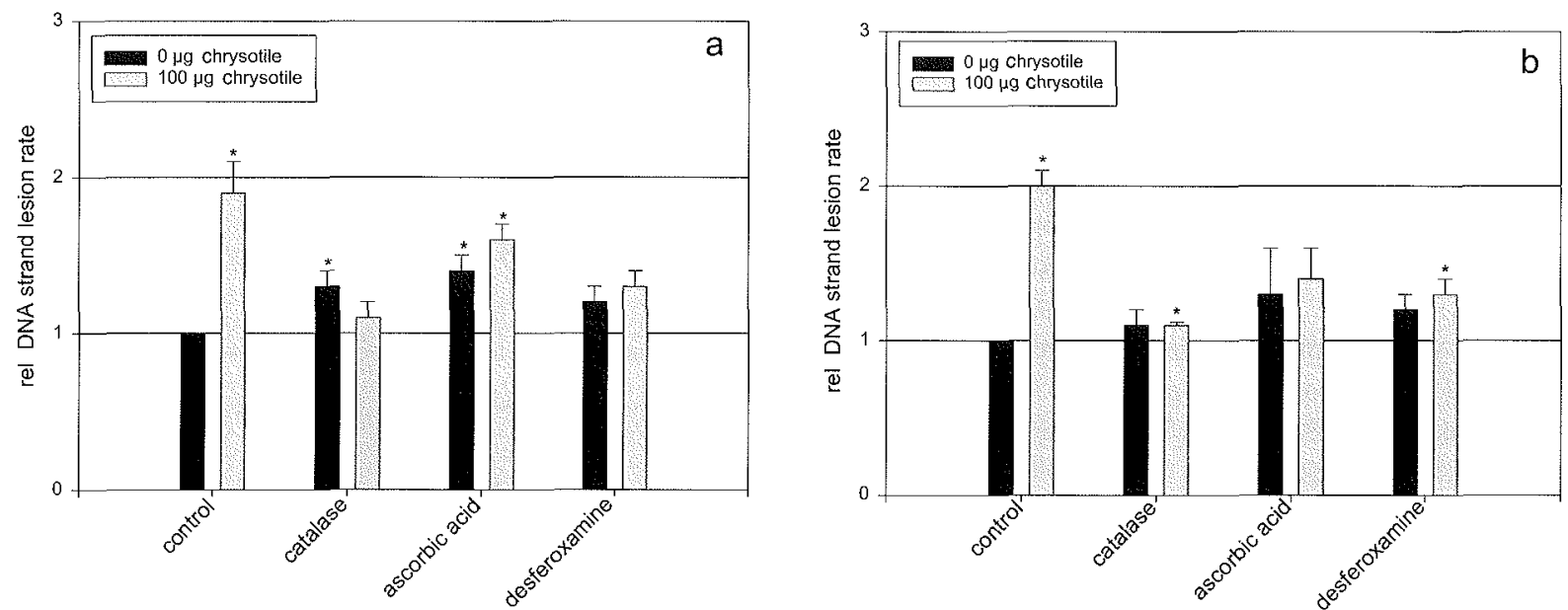

Figure 5. DNA (deoxyribonucleic acid) strand lesions in co-cultured BEAS-2B cells after chrysotile B exposure following the treatment of blood monocytes with antioxidants. Catalase $(200 \mathrm{U} / \mathrm{ml})$, ascorbic acid $(100 \mu \mathrm{M})$, or desferoxamine $(100 \mu \mathrm{M})$ was added to the culture media, and the co-cultured blood monocytes were exposed to chrysotile B at a concentration of $100 \mu \mathrm{g} / 10^{6}$ cells for 3 hours (figure $5 \mathrm{a}$ ) or 48 hours (figure $5 \mathrm{~b}$ ). A maximum inhibition by $85 \%$ on the induction of DNA strand lesions of co-cultured BEAS-2B after a 3-hour exposure period was observed after the addition of catalase. The addition of ascorbic acid induced a $35 \%$ decrease in the DNA strand lesions of co-cultured BEAS-2B cells when compared with the results of the positive control. Similar reaction patterns were observed after 48 hours of chrysotile B exposure. (rel $=$ relative) 
nicotinamide-adenine dinucleotide phosphate (NADPH) oxidase system (25). These highly reactive molecules include superoxide anions $\left(\mathrm{O}_{2}^{-}\right)$, hydrogen peroxide $\left(\mathrm{H}_{2} \mathrm{O}_{2}\right)$, hydroxyl radicals $\left(\mathrm{HO}^{-}\right)$, and hypochloric acid (HOCL), each of which is characterized by a different chemistry and cellular distribution $(26,27)$. In vivo alveolar macrophages are located in the mucous layer surrounding the bronchial epithelial cells. The aim of this study was to investigate whether the exaggerated release of reactive oxygen intermediates of fiber-stimulated macrophages induces DNA lesions in co-cultured epithelial cells.

Consideration of the in vivo situation of the distal respiratory tract served as the basis for our investigations. To model this in vivo situation in a co-culture model, fiber-exposed blood monocytes, cells cytologically related to alveolar macrophages, were placed on a polycarbonate membrane located within a distance of 1 millimeter above the monolayer of the bronchial epithelial cell line BEAS-2B. This in vitro system allowed selective exposure of blood monocytes to asbestos fibers. However, contact of the co-cultured BEAS-2B cells with the fibers was avoided because the latter were unable to penetrate the membrane. A comparison between the asbestos concentration used in our in vitro model and the in vivo situation cannot readily be made as, to our knowledge, no data are available on the ratio of asbestos fibers to alveolar macrophages in vivo. However, it is known that asbestos fibers cause an accumulation of alveolar macrophages in the vicinity of these fibers. Thus it can be assumed that the relationship between blood monocytes and chrysotile $B$ fibers in our in vitro system represents the in vivo situation of normally ventilated areas in the lower respiratory tract of persons exposed to high concentrations of asbestos.

The results of this study show a maximum 3.2-fold increase in the release of reactive oxygen intermediates of blood monocytes after 30 minutes of exposure to chrysotile $B$. In addition, an up to 2.8-fold increase in the level of DNA strand lesions and alkali labile sites was determined in BEAS-2B cells after exposure of co-cultured blood monocytes to chrysotile $B$ at concentrations of 50 and $100 \mu \mathrm{g} / 10^{6}$ cells for up to 48 hours. The induction of DNA strand lesions in co-cultured BEAS-2B cells was inhibited $85 \%(200 \mathrm{U} / \mathrm{ml})$ by the addition of the antioxidant catalase, $80 \%(100 \mu \mathrm{M})$ by desferoxamine, and $35 \%$ $(100 \mu \mathrm{M})$ by ascorbic acid.

The enhanced release of reactive oxygen intermediates observed in acute and chronic pulmonary diseases may be a causal factor in the development of inflammatory mechanisms (25). In addition, our results demonstrate that DNA lesions in co-cultured epithelial cells are caused by the release of reactive oxygen intermediates of asbestos-exposed blood monocytes within an area of up to 1 millimeter. The release of reactive oxygen intermediates may thus also contribute to the pathogenesis of

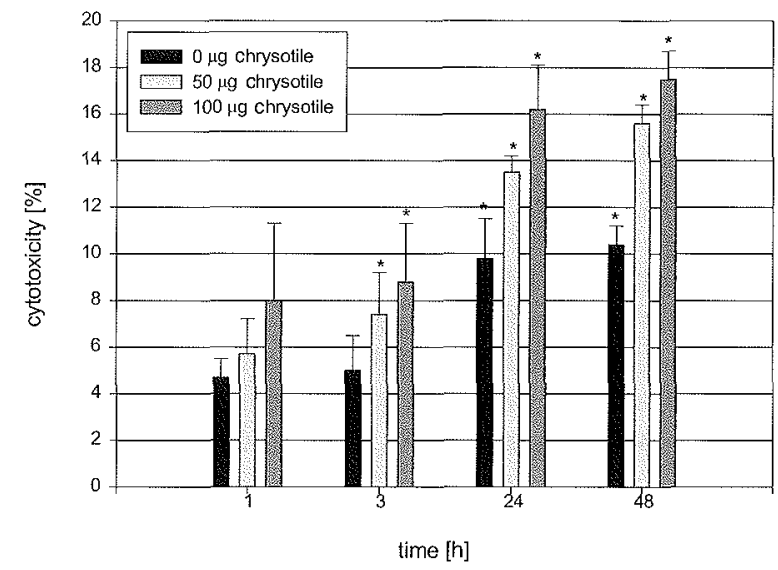

Figure 6. Cytotoxity following chrysotile $B$ exposure of blood monocytes on co-cultured BEAS-2B when checked using the trypan blue exclusion method after $1,3,24$, and 48 hours of exposure at concentrations of 50 and $100 \mu \mathrm{g} / 10^{6} \mathrm{cells}$. The maximum decrease in trypan blue exclusion of co-cultured BEAS-2B cells was detected after the exposure of blood monocytes to $100 \mu \mathrm{g}$ of chrysotile $/ 10^{6}$ cells for an exposure period of 48 hours $(17.47 \%)$.

malignant lung diseases associated with asbestos exposure. These data are supported by the results of previous studies reporting that direct exposure of neutrophil granulocytes causes DNA damage in human and animal target cells. Similarly stimulated phagocytes are able to produce cytogenetic changes in mammalian cells (17). The concept of a mechanism inducing the iron-catalyzed generation of reactive oxygen intermediates after the direct contact of several cell types with asbestos resulting in genotoxicity and cytotoxicity has been supported by the results of various studies $(28,29)$. The inflammatory and mutagenic potential of the asbestos-dependent release of reactive oxygen intermediates is due to the iron-mediated Fenton-reaction, which generates highly reactive hydroxyl radicals. This free radical is able to penetrate directly into the nucleus, and cause base alterations in the DNA. However, the effect of genotoxic substances released by macrophages or monocytes in close contact with asbestos fibers in the lungs of asbestos-exposed persons on the DNA of adjacent bronchial epithelial cells (which may not be in direct contact with fibers) has not yet been investigated.

The different types of DNA damage (DNA strand lesions) determined in this study, which used a modified alkaline elution technique, include DNA single-strand breaks, DNA double-strand breaks, and alkaline labile sites. The latter represent DNA lesions that are converted to DNA strand breaks in the presence of an alkaline $\mathrm{pH}$. Alkali labile sites involve the loss of purine or pyrimidine bases from the sugar-phosphate backbone due to the alkylation of purines, most frequently at the $\mathrm{N} 7$ position of guanine, and lead to a marked increase in the lability of the N-glycosidic bond joining the base to the sugar. If the loss of the respective bases is caused by the 
action of $\mathrm{N}$-glycosidases, the result is the rapid removal of some of the damaged bases (eg, oxidized bases) in the cell (30). The resulting base-free sites are relatively stable under physiological conditions at a half-time of at least 100 hours (31). Under conditions of alkaline elution ( $\mathrm{pH} \mathrm{12.6),} \mathrm{these} \mathrm{sites} \mathrm{are,} \mathrm{however,} \mathrm{converted} \mathrm{to}$ strand breaks within only a few hours, due to an alkalicatalyzed beta elimination of the 3'-phosphate. Direct DNA single-strand breaks may be caused by several mechanisms, including $\mathrm{H}$-abstraction from deoxyribose by reactive oxygen radicals, which labilize the sugarphosphate backbone. DNA double-strand breaks are relatively rare when compared with single-strand breaks. A double-strand break can be defined as a pair of singlestrand breaks located opposed (or located in close proximity) on both strands of the double helix. Sina et al (32) have evaluated the ability of the alkaline elution assay to predict the carcinogenic potential of test substances. Ninety-two percent of the tested substances shown to be (genotoxic) carcinogens in animals induced DNA strand lesions in rat hepatocytes detected by alkaline elution, whereas $85 \%$ of the noncarcinogens were unable to induce DNA strand lesions. An increase in DNA strand lesions is therefore associated (although not quantitatively) with carcinogenicity.

In summary, asbestos-exposed blood monocytes, cells cytologically related to alveolar macrophages, release increased amounts of reactive oxygen intermediates. These intermediates were shown to be able to induce DNA strand lesions in co-cultured bronchial epithelial cells. The lower respiratory tract is covered with epithelial cells, which are frequently cells of origin of bronchial carcinoma. These cells are located in close proximity to alveolar macrophages. We conclude that asbestos-exposed monocytes or macrophages are able to induce DNA strand lesions in adjacent bronchial epithelial cells via the release of reactive oxygen intermediates. This mechanism may contribute to the pathogenesis of apoptosis and oxidative lung carcinogenesis.

\section{Acknowledgments}

This study was supported by a grant from the Federal Ministery of Research and Technology (07INR093) and by the German Research Community (DFG), center grant 519, project B5.

\section{References}

1. Brody AR. Asbestos-induced lung disease. Environ Health Perspect 1993;100:21-30.
2. Champress PE, Cliff G, Lorimer GW. The identification of asbestos. J Microse 1976;108:231-40.

3. Hart GA, Kathman LM, Hesterberg TW. In-vitro cytotoxicity of asbestos and man-made vitreous fibers: role of fiber length, diameter and composition. Carcinogenesis 1994;15:971-7.

4. Lippmann M. Effect of fiber characteristics on lung deposition, retention and disease. Environ Health Perspect 1990; $88: 311-7$

5. Brody AR, Hill LH, Adkins Jr B, O'Connor RW. Chrysotile asbestos inhalation in rats: deposition pattern and reaction of alveolar epithelium and pulmonary macrophages. Am Rev Respir Dis 1981;123:670-9.

6. Brody AR, Roe MW. Deposition pattern of inorganic particles at the alveolar level in the lungs of rats and mice. Am Rev Respir Dis 1983;128:724.

7. Chang LY, Overby LH, Brody AR, Crapo JD. Progressive lung cell reactions and extracellular matrix production after a brief exposure to asbestos. Am J Pathol 1988;131:156-70.

8. Doll NJ, Stankus RP, Goldbach S, Salvaggio JE. In-vitro effect of asbestos fibers on polymorphonuclear leukocyte function. Int Arch Allergy Appl Immunol 1982;68:17-21.

9. Hansen K, Mossman BT. Generation of superoxide from alveolar macrophages exposed to asbestiform and nonfibrous particles. Cancer Res 1987:47:1681—6.

10. Quinlan TR, Marsh JP, Janssen YMW, Borm PA, Mossman BT. Oxygen radicals and asbestos-mediated disease. Environ Heath Perspect 1994;102:200-6.

11. Cheeseman KH. Lipid peroxidation in biological systems. In: Halliwell B, Aruoma OI, editors. DNA and free radicals. London: Ellis Horwood, 1993:141—63.

12. Cheeseman KH, Slater TF. An introduction to free radical biochemistry. Br Med Bull 1993;49:481-93.

13. Kinnula VL, Raivio KO, Linnainmaa K, Ekman A, Klockars $M$. Neutrophil and asbestos fiber-induced cytotoxicity in cultured human mesothelial and bronchial epithelial cells. Free Radic Biol Med 1995;18:391—9.

14. Kamp DW, Dunn MM, Sbalchiero JS, Knap AM, Weitzman SA. Contrasting effects of alveolar macrophages and neutrophils on asbestos-induced pulmonary epithelial cell injury. Am J Physiol 1994;266 (1 Pt 1):L84-L91.

15. Kamp DW, Graceffa P, Pryor WA, Weitzman SA. The role of free radicals in asbestos-induced diseases. Free Radic Biol Med 1992;12:293-315.

16. Kamp DW, Dunne M, Weitzman SA, Dunn MM. The interction of asbestos and neutrophils injures cultured human pulmonary epithelial cells: role of hydrogen peroxide. J Lab Clin Med 1989;114:604-12.

17. Weitberg AB, Weitzman SA, Destrempes M, Latt SA, Stossel TP. Stimulated human phagocytes produce cytogenetic changes in cultured mammalian cells. N Engl J Med 1983;308:2630.

18. Ziegler-Skylakakis K, Andrae U. Mutagenicity of hydrogen peroxide in V79 Chinese hamster cells. Mutat Res 1987; 192:65-7.

19. Halliwell B, Aruoma O. DNA damage by oxygen-derived species. FEBS Lett 1991;281:9-19.

20. Böyum A. Isolation of mononuclear cells and granulocytes from human blood. Scand J Clin Invest 1986;21:77-89.

21. Ke Y, Reddel RR, Gerwin BI, Miyashita M, McMenamin M, Lechner JF, et al. Human bronchial epithelial cells with integrated SV 40 virus antigen genes retain the ability to undergo squamous differentiation. Differentiation 1988;38:60—6.

22. Miles PR, Lee P, Trush MA, Van Dyke K. Chemiluminescence associated with phagocytosis of foreign particles in 
rabbit alveolar macrophages. Life Sci 1977;20:165-70.

23. Hengstler JG, Hengst A, Fuchs J, Tanner B, Pohl J, Oesch F. Induction of DNA crosslinks and DNA strand lesions by cyclophosphamide after activation by cyto-chrome P450 2B1. Mutat Res 1997;373:215-23.

24. Sibille Y, Reynolds HY. Macrophages and polymorphonuclear neutrophils in lung defense and injury. Am Rev Respir Dis 1990;141:471-501.

25. Bast A, Haenen G, Doelman CJA. Oxidants and antioxidants: state of the art. Am J Med 1991;91:(3C)2S-13S

26. Guyton KZ, Kensler TW. Oxidative mechanisms in carcinogenesis. Br Med Bull 1993;49:523-44.

27. McDonald RJ, Pan LC, George JAS, Hyde DM, Ducore JM. Hydrogen peroxide induces DNA single strand breaks in respiratory epithelial cells. Inflammation 1993;17:715 -22.

28. Kamp DW, Israbian VA, Preusen SE, Zhang CX, Weitzman SA. Asbestos causes DNA strand breaks in cultured pulmo- nary epithelial cells: role of iron-catalysed free radicals. Am J Physiol 1995;268:L471-L480.

29. Mossman BT, Marsh JP. Evidence supporting a role for active oxygen species in asbestos-induced toxicity and lung disease. Environ Health Perspect 1989;81:91-4.

30. Karran P, Hjelmgren T, Lindahl T. Induction of a DNA glycosylase for N-methy-lated purines is part of the adaptive response to alkylating agents. Nature $1982 ; 296: 770-3$.

31. Lindahl T, Andersson A. Rate of chain breakage at apurinic sites in double-stranded deoxyribonucleic acid. Biochemistry 1972;11:3618-23.

32. Sina JF, Bean CL, Dysart GR, Taylor VJ, Bradley MO. Evaluation of the alkaline elution/rat hepatocyte assay as a predictor of carcinogenic/mutagenic potential. Mutat Res 1983; 113:357-91

Received for publication: 8 September 1998 